\title{
Flexibility of operations in developing countries with Industry 4.0. A systematic review of literature
}

\author{
Diana C. Tascón ${ }^{a *}$ (D), Gonzalo Mejía ${ }^{\mathrm{b}}$ (D), Daniel Rojas-Sánchez ${ }^{\mathrm{b}}$ \\ aUniversidad Distrital Francisco José de Caldas, Bogotá, Colombia \\ bUniversidad de La Sabana, Chia, Colombia \\ *dctasconh@udistrital.edu.co
}

\begin{abstract}
Paper aims: To provide guidelines on current state of the literature on aspects related to the implementation of Industry 4.0 (14.0) for operations flexibility in emerging economies, and derived from this, propose a conceptual framework for the analysis of the main topics studied.

Originality: Based on previous literature reviews on related topics (14.0 and flexibility), we recognized an opportunity to focus on developing countries which until now has not been documented.

Research method: We carried out a systematic review of the literature together with a topic cluster analysis.

Main findings: The study revealed that there is a perceived consensus on how Industry 4.0 technologies can impact flexibility in emerging countries. Cloud computing is by far the most adopted technology despite the fact that there is a wide concern about security issues. The use of other technologies and their impact appears to be incipient.

Implications for theory and practice: The study presented here can be used as a starting point for new directions of research in terms of adoption of these technologies and new applications developed and/or customized to the realities of emerging countries.
\end{abstract}

Keywords

Industry 4.0. Developing countries. Flexibility. Supply chain. Enterprises.

How to cite this article: Tascón, D. C., Mejía, G., \& Rojas-Sánchez, D. (2022). Flexibility of operations in developing countries with industry 4.0. A systematic review of literature. Production, 32, e20210055. https://doi.org/10.1590/01036513.20210055.

Received: May 30, 2021; Accepted: Nov. 24, 2021.

\section{Introduction}

Industry 4.0 is a term coined at the Hannover-Messe industrial trade fair in 2011 that involves the digital innovations that are transforming the society we live in. Industry 4.0, represents a radical shift towards interconnected organizations, aimed at greater adaptability and responsiveness not only in terms of manufacturing and logistics processes but also in terms of organizations. One of the goals is the creation of automated production and manufacturing systems with decision making capabilities (smart manufacturing). Critical to this is the integration of systems and processes through Internet of Things (loT), the development of Cyber Physical Systems (CPS), and the support of Big Data and Analytics, Artificial Intelligence and Cloud Computing (Dolgui et al., 2019).

Industry 4.0 seems to be the response to the today's competitive world that imposes increasingly stringent requirements, such as tighter deadlines, competitive inventory levels, uncertain demand management, process standardization, and product diversity. This results in constant and new challenges for companies, as they are compelled to stay at the forefront of management strategies that efficiently articulate recent technological developments in their daily operations. 
However, up to date no defined framework for Industry 4.0 has been implemented or documented to the best of our knowledge. As of today, most implementations are a combination of technologies that coexist with legacy computer systems and organizations. An issue that is frequently overlooked is flexibility. This term has been widely used since the birth of Flexible Manufacturing Systems (FMS) whose ultimate goal was to bring customized products at higher rates. Since then, terms such as "flexibility", "agility", "reconfigurability", "resilience" and "adaptability" have been used indistinctly.

The implementation of industry 4.0 represents a challenge of considerable magnitude for developing countries. There has been a (relatively recent) interest in studying the implications of the use of 4.0 technologies on the performance of operations in these economies, with which various initiatives have emerged (governmental, industrial, academic, etc.), to provide inputs / guidelines in this regard. In the literature there has been a growing interest in the related documentation, thus we considered pertinent at this point to make a systematic review to capture the state of the art and at the same time provide a basis for directions for future research and/or implementations.

\section{Research methodology}

Following-up on the previous work by Tascón \& Mejía (2021a, b), we carried out a systematic review of the literature focused on applications of Industry 4.0 on manufacturing, logistics and public systems in developing countries.

In this paper we also explored clustering techniques. To do so, we used the SciVal tool provided by Elsevier ${ }^{\mathrm{mm}}$ and the VOSviewer which is an analytics tool for co-occurrence analysis. Scival is a web-based analytics tool for bibliometric analysis. The methodology steps are summarized in Figure 1.

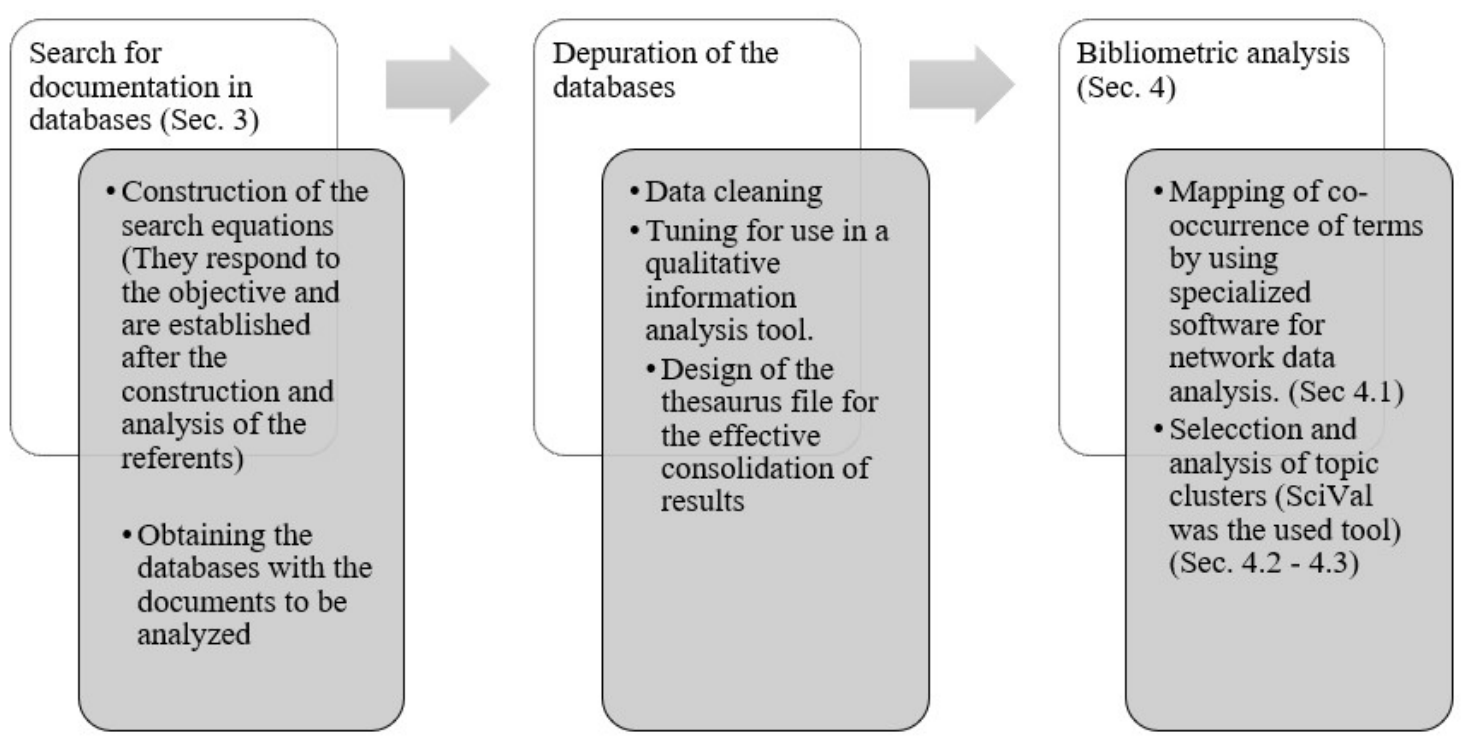

Figure 1. Stages of bibliometric analysis. Source: Adapted from Tascón \& Mejía (2021a).

Derived from this bibliometric analysis, we propose a reference framework (Sec. 5) for the understanding and analysis of the main concerns and several aspects studied in the literature regarding the flexibility of operations in developing countries in the context of industry 4.0.

\section{Search and debugging of documents in databases.}

The first step of this study was the design of the search equation. Thus, taking into consideration that the central object of this study is the strategies that promote flexibility (adaptability, resilience, response capacity, etc.) of manufacturing system in the context of developing countries in the Industry 4.0 context, we arrived in 
the search equation presented in Table 1 . The search equation contains terms related to (i) flexibility such as agility, reconfigurability, adaptability and resilience, (ii) the industry 4.0 and its variations such as "industrie", (iii) the technologies such as cloud computing, big data, and loT, among others, (iii) emerging and/or developing countries for obvious reasons and, (iv) terms related to the industrial sector such as organization, manufacturing, supply chain, etc. We performed the search in the well-known Scopus database.

It should be noted that in this search equation we incorporated the "industry 4.0" term, either explicitly or through some of its elements or main components, as is the case of lnternet of Things (10T), cloud computing, and digital transformation. A database set, consisting of 94 documents was obtained.

Table 1. Search equation.

\begin{tabular}{|c|c|}
\hline Search equation & Documents found \\
\hline 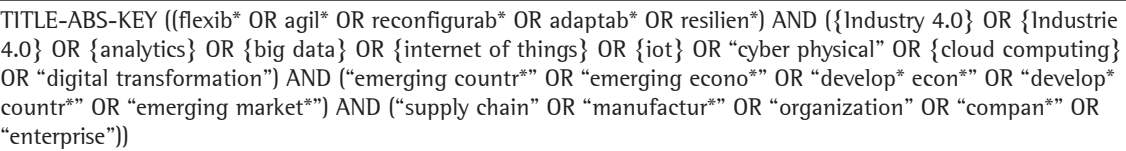 & 94 \\
\hline
\end{tabular}

\section{Bibliometric analysis}

\subsection{Analysis of co-occurrences}

A co-occurrence of terms analysis was run in VOSviewer, and the map shown in Figure 2 was obtained.

The analysis of co-occurrences shows the interrelationships that exists between the keywords and the frequency with which they appear. The size of the nodes is directly related to the number of documents that contain the term; the arcs are generated from the "minimum of co-occurrences" that was parameterized colors illustrate the existence of document clusters. From this perspective, the existence of three clusters is evidenced: these were cluster 1: artificial intelligence, big data, commerce, human and internet of things. cluster 2: competition, developing countries, digital transformation, industry 4.0 and supply chain; and cluster 3: cloud computing, developed countries, information technology. These clusters show the correlation of research interests and then will be taken as a guide for the development of a framework for the analysis of the problems studied.

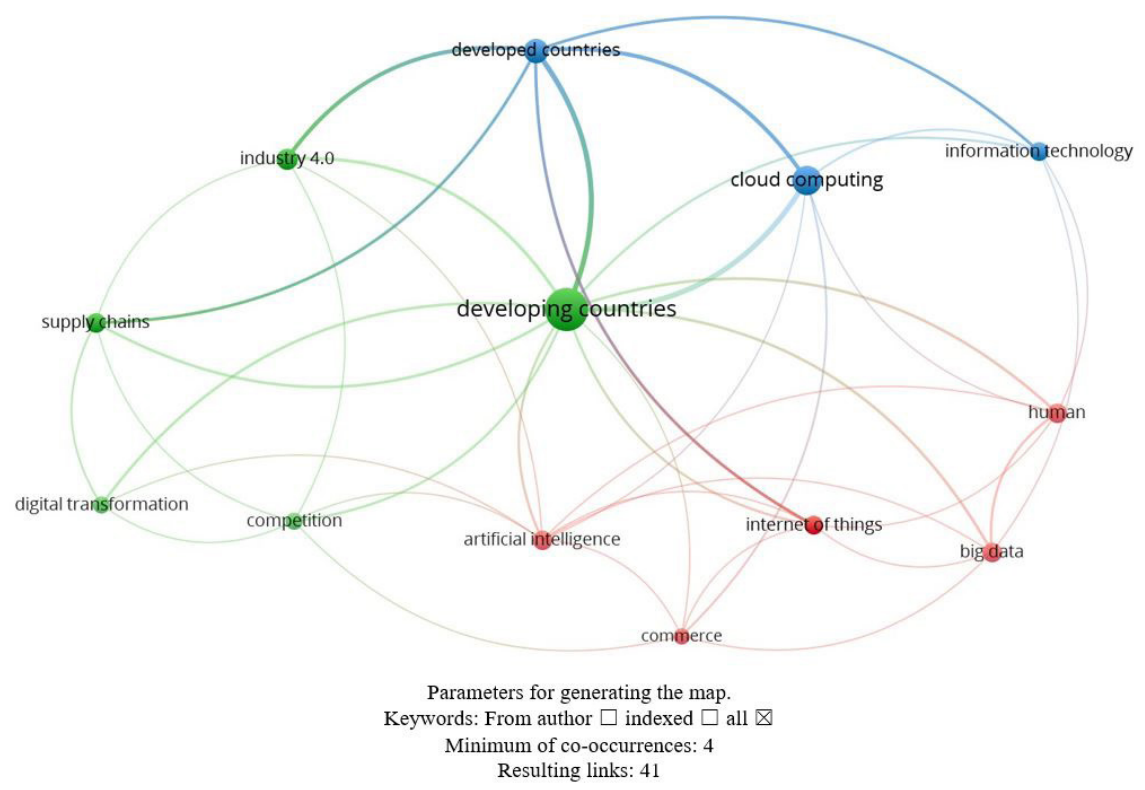

Figure 2. Co-occurrence map, search equation. 


\subsection{Topic clusters selection}

As previously mentioned, to guide the development of a more specific review of the documents found, we used SciVal (by Elsevier Solutions), to generate a set of Topic Clusters (TC) from the database under study. A TC is an aggregation of topics with similar research interest into broader, higher-level areas of research (Elsevier Solutions, 2021).

For the case, the tool provided $28 \mathrm{TC}$, within which we select those that have the greatest affinity with the objective of the present study. Also, after a preliminary review of documents, we included an additional TC (education). The selection is presented in Table 2 (the first column indicates the coding of the TC given in SciVal).

In the next session, the results of the review carried out based on the definition of the defined TC will be presented.

Table 2. Topic clusters selection.

\begin{tabular}{ccc}
\hline TC. Number & Topic Cluster & Source of topic cluster \\
\hline TC. 254 & Industry; Information Systems & SciVal \\
TC. 24 & Industry; Innovation; Entrepreneurship & SciVal \\
TC. 146 & Supply Chains; Supply Chain Management; Industry & SciVal \\
-- & Industry; Education & Authors \\
\hline
\end{tabular}

\subsection{Analysis and review}

\subsubsection{Information systems}

In this topic cluster, 13 articles were found, most of them addressing the topic of cloud computing. Cloud computing is a term referring to services and resources delivered over the Internet. Cloud computing relies on distributed and parallel computing to provide on-demand access to resources such as hardware, software, and databases. Cloud computing is a broad term that includes several concepts such as software-as-a-service (SaaS), platform-as-a-service (PaaS), or infrastructure-as-a-service (laaS) (Lal \& Bharadwaj, 2016). Cloud computing offers companies almost unlimited and scalable capabilities without the need of investing on hardware, software licensing or personnel training. This is a technology that changes the traditional hosting and local operation of software and hardware (Lal \& Bharadwaj, 2016; Mallmann \& Maçada, 2018).

Flexibility in cloud is generally related to the ability to access to services on demand and from different locations, eliminating the need of on-site hardware and software (Lal \& Bharadwaj, 2016). Flexibility in the context of information systems and cloud computing is closely linked to organizational flexibility (Lal \& Bharadwaj, 2016). In essence, cloud services, that operate on demand, are a key leveraging factor in the organizational flexibility. This latter term refers to the ability of an organization to respond to external changes quickly and efficiently. The study of Lal \& Bharadwaj (2016) reveals that cloud-computing adoption can positively impact organizational flexibility in its four pillars: economic, processes, marketing and performance given that the right environment is provided.

The reviewed papers follow the TOE approach (AlBar \& Hoque, 2019; Kumar et al., 2017) that explains the technology adoption from perspectives of technology, organization and environment. Despite its many advantages, cloud computing has not been widely adopted in emerging countries due to several reasons that are examined in this bibliographic study.

Most of the reviewed papers study either the drivers for adoption of this technology or the barriers in their implementation in an emerging country or region. No multi-country study was found. In particular, as Small and Medium Enterprises (SMEs) constitute the majority of companies in emerging countries, it is no surprise that several studies address this topic (Khayer et al., 2020; Kumar et al., 2017; Wilson et al., 2016). These studies either study the drivers for adoption (Khayer et al., 2020), the factors that affect the successful implementation (Kumar et al., 2017; Wilson et al., 2016) or the barriers (Kumar et al., 2017). As in other studies (i.e., Dalenogare et al., 2018), drivers include scalability and flexibility, organization performance, cost reduction and government policies and competition pressure. Authors such as Limani et al. (2018) point out that survival should also be considered as a main driver in emerging countries. On the other hand, top management support, availability of broadband, compatibility with existing systems, management of change and educated and trained personnel are perceived as the factors for successful adoption in SMEs. Main concerns involve vendor lock-in, loss security, perceived lack 
of reliability, poor bandwidth. governmental policies and limited availability (Wilson et al., 2016). Similar results were reported in Alanezi (2018), and AlBar \& Hoque (2019) who studied the adoption of cloud computing in large public and private companies. However, in large companies as expected, bandwidth and availability were not significant factors for the adoption of cloud computing. Another perspective is based on secondary sources. For example, Dalenogare et al. (2018) performed an analysis of public databases on the topic of adoption of Industry 4.0 (including cloud computing) in Brazil. They found that cloud computing has not been widely adopted in Brazil despite that top managers identify their benefits. Bazi et al. (2018) investigated the drivers for cloud computing in Iran based on a review of the literature. Their findings were validated by experts.

Other studies explore the adoption of cloud computing on large non-profit organizations: for example, Mallmann \& Maçada (2018) studied the barriers for adoption in the healthcare sector in Brazil. The main findings of their surveys was that security issues and availability outweigh the potential benefits of cloud computing. Al-Maatouk et al. (2018) proposed a framework for cloud computing implementation on the public organizations in Malaysia. They also found that security was the main concern among the respondents. The education sector (both public and private) appears to be more enthusiastic about the implementation of cloud computing. This technology has brought important benefits for teaching and research, whose in-premise costs may be prohibitive for many public and private institutions (Milian et al., 2017). The study of Alghushami et al. (2020) in the education sector of Yemen found more or less the same drivers and barriers for the adoption of cloud technologies as in other organizations of emerging countries. This work points out that tribal (e.g., cultural) aspects were also important barriers.

The last reviewed paper by Saide \& Sheng (2020), not related exclusively to cloud computing adoption investigates the role of Big Data and Knowledge Management and information systems company innovation in Indonesia. The study shows mixed results in the sense that no relation could be established between the adoption of Big Data in process innovation.

Summarizing, despite of inherent benefits, cloud computing has a long way for full adoption in emerging countries due to infrastructure (e.g., bandwidth), culture (e.g., lack of knowledge and training) and security concerns. Table 3, condenses the results of this bibliometric study.

Table 3. Summary of the "Industry; Information Systems" topic cluster bibliometric study.

\begin{tabular}{|c|c|c|}
\hline Specific topic & Authors & Methodology \\
\hline Cloud computing adoption in SMEs India & Kumar et al. (2017) & Surveys \\
\hline Cloud computing adoption in public and private hospitals Brazil & Mallmann \& Maçada, (2018) & Interview \\
\hline Cloud computing adoption in Enterprises Saudi Arabia & AlBar \& Hoque (2019) & Online Survey \\
\hline Cloud computing adoption in SMEs Bangladesh & Khayer et al. (2020) & Surveys \\
\hline Cloud computing adoption in SMEs Tamil Nadu & Wilson et al. (2016) & Online Survey \\
\hline Adoption and benefits of Industry 4.0 in Industry Brazil & Dalenogare et al. (2018) & Metadata analysis \\
\hline Digital Transformation Kosovo & Limani et al. (2018) & Collected Data (Survey) \\
\hline $\begin{array}{l}\text { Cloud computing adoption in Public and Private organizations } \\
\text { (Universities) Saudi Arabia }\end{array}$ & Alanezi (2018) & Survey \\
\hline Cloud computing adoption in Public sector Malaysia & Al-Maatouk et al. (2018) & Interviews / Survey \\
\hline Cloud computing Risks and Uncertainties & Milian et al. (2017) & Literature Review \\
\hline Cloud computing adoption in Universities Yemen & Alghushami et al. (2020) & Survey \\
\hline Business Process Innovation in the Big Data Indonesia & Saide \& Sheng (2020), & Survey \\
\hline Cloud computing best practices Iran & Bazi et al. (2018) & Survey (Experts) \\
\hline
\end{tabular}

\subsubsection{Innovation and entrepreneurship}

In this topic cluster, 10 documents were found: the main areas of knowledge from which the studies were carried out were: computer science, social sciences, decision sciences, and business management. Several of the documents in this topic emphasize in the need of digital transformation or digitalization (El-Telbany et al., 2020; Quayson et al., 2020; Yıldırım \& Demirbağ, 2020) for the improvement of flexibility or productivity in emerging economies. Other papers of the reviewed literature study the effect of or over organizational learning / knowledge (Arias-Pérez et al., 2021; Kacani, 2017; Lin \& Hsu, 2017; Tjakraatmadja \& Handayani, 2019). Another work that studies new ways of assessing economic developing is that of Al-Roubaie \& Sarea, (2020). In other research, Yıldırım \& Demirbağ (2020) focused on the study of real practices for Industry 4.0 implementation.

It is also noticeable that most of the literature in this topic follows case study approaches (El-Telbany et al., 2020; Kacani, 2017; Quayson et al., 2020; Tjakraatmadja \& Handayani, 2019), surveys and structural equation modeling were also used. 
About digital transformation (DT) Quayson et al. (2020) found out that there are some foundations and successful cases of 14.0 technologies in developing countries and remarked the need for working on some weaknesses as the case of effective use of existing platform technologies, (e.g., blockchain, artificial intelligence, global positioning, 5G and cyber-physical systems). These authors also present a concern about the roles and effectiveness of various stakeholders and institutions in the digital transformation, as NGOs, governments, and local communities. In order to accomplish DT growth, El-Telbany et al. (2020) point out that Vision \& Strategy, Competitiveness \& Agility, Organization, Data \& Analytics, and Operational Excellence are key development areas. Turkyilmaz et al. (2021) through a review of the literature, studied the correlation between Industry 4.0 and industrial development of economies, the focused their study on small and medium-sized enterprises (SMSe) in Kazakhstan, and provided a SWOT (Strengths, Weaknesses, Opportunities and Threats) analysis from which they presented some suggestions that include the need to increase awareness about Industry 4.0 and digital literacy of employees.

Arias-Pérez et al. (2021) analyzed the mediating effect of the open innovation processes of knowledge acquisition and exploitation as external embeddedness strategy on the relationships between strategic orientation toward digitalization and the three dimensions of the innovation capability: client, marketing and technology, they concluded that strategic orientation toward digitalization has an effect on innovation capability, with a greater impact on the client and technology dimensions than on the marketing dimension; also in the line of knowledge / learning Tjakraatmadja \& Handayani (2019) studied education technology and its relation with better learning performance and meet educational needs in emerging countries, this paper is also mentioned in the "education" TC review. Kacani (2017) focused on the importance of knowledge flexibility in enhancing the production activity in the specific clothing manufacturing enterprises beyond the production segment of the supply chain. They built a model that includes both the channels and the factors affecting the transfer of knowledge from the head office to their subsidiaries located in developing countries. Lin \& Hsu (2017) studied strategy planning in which the elements of Industry 4.0 can be incorporated to improve operations flexibility and performance. After analyzing survey data, they provided a set of categories to classified traditional industries in Taiwan. The proposed categories involve aspects as global competitiveness and degree of free trade influence. Al-Roubaie \& Sarea (2020) analyze the need of rethinking development. They mention that this aspect requires adapting new strategies for development to support labor market flexibility and strengthen digital readiness. These authors highlight the importance of knowledge and technology for economic development. In the last paper considered in this TC, Yıldırım \& Demirbağ (2020) projected a research process that includes structured interviews, a digital maturity model, observation of production facilities, analysis of company's web sites, and an assessment of news of companies on the web. These authors made a comparative case analysis considering two white goods companies in Turkey. The comparisons were made under the approach of "digital maturity" scores. Table 4, summarizes the results of this TC bibliometric study.

Table 4. Summary of the "Industry; Innovation; Entrepreneurship" topic cluster bibliometric study.

\begin{tabular}{|c|c|c|}
\hline Specific topic & Authors & Methodology \\
\hline Digital transformation, smallholder farmers in developing countries & Quayson et al. (2020) & Cases studies \\
\hline Digital transformation, emerging economies, Egypt & El-Telbany et al. (2020) & Cases studies \\
\hline $\begin{array}{l}\text { Digitalization, Industry } 4.0 \text { for Small and medium-sized enterprises in } \\
\text { Kazakhstan }\end{array}$ & Turkyilmaz et al. (2021) & Literature review \\
\hline Digitalization, knowledge acquisition and innovation & Arias-Pérez et al. (2021) & $\begin{array}{l}\text { Structural equation modeling } \\
\text { design based on survey }\end{array}$ \\
\hline Organizational learning, Indonesian education technology startups & Tjakraatmadja \& Handayani (2019) & $\begin{array}{l}\text { Multiple case study research, } \\
\text { in-depth interviews }\end{array}$ \\
\hline $\begin{array}{l}\text { Knowledge flexibility, clothing manufacturing enterprises located in } \\
\text { developing countries }\end{array}$ & Kacani, (2017) & Case study, knowledge modeling \\
\hline Organizational strategy, Taiwan's traditional industry & Lin \& Hsu (2017) & Survey \\
\hline Strategies for economic development in Muslim Societies & Al-Roubaie \& Sarea (2020) & Qualitative research \\
\hline $\begin{array}{l}\text { Study of real Industry } 4.0 \text { practices for developing countries, Turkish } \\
\text { white goods manufacturing }\end{array}$ & Yıldırım \& Demirbağ (2020) & Cases studies \\
\hline
\end{tabular}

\subsubsection{Supply chains and supply chain management}

In this topic cluster, 9 articles were found: the areas of knowledge from which the studies were carried out were: business, management $\&$ accounting, engineering, and agriculture \& biological sciences. It is found a noticeable interest over Supply Chain Integration (Bag et al., 2018; Irfan \& Wang, 2019; Raut et al., 2018), 
strategies to increase productivity (Charrua-Santos et al., 2020; Irfan \& Wang, 2019; Varela et al., 2019), such as Lean Production (Charrua-Santos et al., 2020; Varela et al., 2019) and automatization of processes (Araújo et al., 2018), sustainability aspects (Bag et al., 2018, 2021) and study of disruption drivers (Mithun Ali et al., 2021). Some of main general aspects of this documents are synthesized next.

Charrua-Santos et al. (2020), explored how Lean Production (LP) and Industry 4.0 integration could contribute to increasing the desirable flexibility and productivity. The authors conducted a survey in 87 manufacturing companies located in Angola and found a that the implementation of LP and Industry 4.0 concepts are not being uniformed in terms of companies' size and geography. This reinforces the generalized idea of this improvement opportunity for developing countries. Some other authors studied the contribution to increase productivity and/or flexibility by increasing capabilities, in this particular matter, Irfan \& Wang (2019) analyzed the effects of data-driven capabilities on supply chain integration and competitive performance of firms in the food and beverages industry in Pakistan. They affirm that the cloud-based sharing of data can improve the operational performance of channel members while reducing their overall cost of operations. Also a documented way to improve performance and productivity is processes automatization: Araújo et al. (2018) worked on an automatization project based on Lean Production with the "leagile" emerging concept, focused on the prompt response to turbulent and dynamic markets.

Reinforcing the perception of the need of digital integration of Supply Chains (horizontal, vertical and end-to-end), now in a sustainable way. Bag et al. (2018) emphasizing that strategies for Industry 4.0 should be refined and detailed to develop economic and social systems that can act flexibly to sudden changes in the system, so they ended up identifying a set of Industry 4.0 enablers of supply chain sustainability. Raut et al. (2018) analyzed the proposed cloud computing integration and external integration effects on the relationship between the integration of supply chain and business performance of the organization in the Indian context. They summarized that production flexibility is an essential factor for operational business performance, followed by customer integration, supplier integration, product quality, internal integration, and on-time delivery. Mithun Ali et al. (2021) studied the supply chain disruption factors and drivers. They developed a framework to identify, analyze, and to assess it. The ready-made garment industry in Bangladesh was taken as an industrial example. Qvist-Sørensen (2020), Surajbali et al. (2015), and Boukhris (2018) concluded that 14.0 completion is required for industries of all sized to participate and survive in the new commercial environment characterized by intense competition. The research community on this topic pointed out that the ongoing digital transformation facilitates a new business model for machining and equipment manufacturers in Eastern European countries. Servitization will also benefit industrial companies, generating higher revenues and integrating more effectively into their customers' value chain and improving their competitiveness.

Table 5 summarizes the results of this TC bibliometric study.

Table 5. Summary of the "Supply Chains; Supply Chain Management; Industry" topic cluster bibliometric study.

\begin{tabular}{|c|c|c|}
\hline Specific topic & Authors & Methodology \\
\hline Lean production, survey in Angola industries & Charrua-Santos et al. (2020) & Survey \\
\hline $\begin{array}{l}\text { Supply Chain Integration, Lean manufacturing, data-driven } \\
\text { supply chain operations, survey in Pakistani industries }\end{array}$ & Irfan \& Wang (2019) & Structural equation modeling, Survey \\
\hline $\begin{array}{l}\text { Processes automatization, Lean Production, Agile } \\
\text { Manufacturing, (leagil). }\end{array}$ & Araújo et al. (2018) & Simulation, production line design \\
\hline Supply Chain Integration, Supply Chain Sustainability & Bag et al. (2018) & Systematic literature review \\
\hline Supply Chain Integration, Cloud Computing & Raut et al. (2018) & $\begin{array}{l}\text { Structural equation modeling, and artificial neural } \\
\text { network }\end{array}$ \\
\hline $\begin{array}{l}\text { Supply Chain disruption, ready-made garment industry in } \\
\text { Bangladesh. }\end{array}$ & Mithun Ali et al. (2021) & $\begin{array}{l}\text { Delphi method and the fuzzy analytic hierarchy } \\
\text { process }\end{array}$ \\
\hline $\begin{array}{l}\text { Industry } 4.0 \text { development and implementation in } \\
\text { developing countries, Germany }\end{array}$ & Qvist-Sørensen (2020) & Case study \\
\hline $\begin{array}{l}\text { Establishing proper collaborative networks for service- } \\
\text { enhanced products, Germany }\end{array}$ & Surajbali et al. (2015) & Cases studies \\
\hline Emerging Technologies for Developing Countries, India. & Boukhris (2018) & Theoretical study \\
\hline
\end{tabular}

\subsubsection{Education}

This part of the literature review shows a specific cluster around education and industry development and implementation in the emerging economies. Cloud computing is the topic that seems to be the most relevant 
due to the attention given to it, as it is present in almost all the articles analyzed. Regarding the implementation of digital technologies in the industry, the results are diverse. At least one paper (Chien et al., 2017) concludes that for most developing countries is necessary to go through an intermediate phase between 13.0 and 14.0, stage they call 13.5, as the conditions for full implementation are nor given yet. For others, 14.0 implementation is the only way for enterprises to survive. Several of the documents studied present frameworks for decision-making concerning the implementation of digital technologies and the deepening of the fourth industrial revolution.

Cloud education is presented by Sabi et al. (2018), Harlie et al. (2019) and Fergencs et al. (2020). Sabi et al. (2018) affirm that given the deficiencies in information technology systems in universities in developing countries, Cloud Computing appears to be a formidable tool to improve teaching, enhance research and boost collaboration in universities in developing countries without the need for on-campus presence; the study explores the perceptions of staff members in 11 Ugandan universities, the finding show the lack of infrastructure, staff training, and issues related to the risk of data loss are the main barriers to using this technology. For Harlie et al. (2019) the public sector is experiencing remarkable growth in information technologies, universities should modify conventional teaching methods using new ways based on digitization. These authors and many others claim that in the era of the Internet of Things (loT), the role of information technologies is vital to strengthen the core competencies of students and the competitiveness of universities. the study show that the implementation of new technologies increases the exchange of information, has a positive impact on the development of industry, and encourages higher education institutions to increase their investments. The success of the information systems model is the starting point for the acceptance of these technologies, but it requires enormous efforts to find adequate funding and sustained political will. Lastly, Fergencs et al. (2020) study digital learning in developing countries where poverty and inequality hinder the implementation of technology-assisted teaching, the paper uncover the obstacles to successfully implementing a learning management system for supplementing mathematics education. The results indicate that modern technical equipment to school practices and digital platforms in education is still an ongoing process in many developing countries. The lack of convincement of some actors is one of the most remarkable barriers. Table 6 summarizes the results of this TC bibliometric study.

Table 6. Summary of the "Education" topic cluster bibliometric study.

\begin{tabular}{|c|c|c|}
\hline Specific topic & Authors & Methodology \\
\hline $\begin{array}{l}\text { The lmplementation of digital } \\
\text { technologies: Industry } 3.5 \text {, from } 13.0 \text { to } \\
\text { 14.0, Taiwan }\end{array}$ & Dalenogare et al. (2018) & Empirical studies in high- tech manufacturing \\
\hline $\begin{array}{l}\text { Cloud Computing implementation and } \\
\text { use, Uganda }\end{array}$ & Sabi et al. (2018) & Survey \\
\hline Digital education, loT, Indonesia & Harlie et al. (2019) & $\begin{array}{l}\text { Structural Equation Model tested on end-users consisting of } \\
150 \text { public university officers }\end{array}$ \\
\hline $\begin{array}{l}\text { Digital Technology barriers } \\
\text { implementation for basic Learning in } \\
\text { South Africa }\end{array}$ & Fergencs et al. (2020) & Survey \\
\hline $\begin{array}{l}\text { Emerging Technologies for Developing } \\
\text { Countries, India. }\end{array}$ & Boukhris (2018) & Theoretical study \\
\hline $\begin{array}{l}\text { Organizational learning, Indonesian } \\
\text { education technology startups }\end{array}$ & Tjakraatmadja \& Handayani (2019) & Multiple case study research, in-depth interviews \\
\hline
\end{tabular}

\section{Conceptual framework}

As mentioned above, the co-occurrence map highlights the links between research interests (from the analysis of the co-occurrence of the terms). This information was taken as a starting point to structure the framework, specifically these terms and their co-occurrence gave the basis for the definition of input elements, while the analysis of TCs, gives support to the elements from which the status of the implementation of industry 4.0 elements that improve flexibility in developing countries can be evaluated. Figure 3 shows the relationships between the TCs and the co-occurrence graph.

The TC on information system can be mapped to the blue elements of the co-occurrence graph, excluding the node of "developing countries" which is common in all the studies. The second TC on innovation can be related to the "competition" and DT nodes. Finally, the third TC on supply chains and industries can be mapped to the green elements which contains the application sectors where 14.0 can be, or it is being used. The TC on education, not considered by either SciVal or VosViewer is no surprise that is not on the diagram. 
Based on the research described above, we present a conceptual framework (shown in Figure 4). The main findings related with this framework are pointed out below.

Inputs: the study reveals that the main components that are used and influence the flexibility strategies and operation of organizations in emerging countries are Internet of Things, Big Data, Cloud Computing and Artificial Intelligence/Machine Learning. Among those elements, Cloud Computing dominates the others, and it is used in a wide spectrum of organizations.

Moderator factors: those include human and socio demographic aspects, and costs and/or availability of technologies (Mallmann \& Maçada, 2018). Human factors encompass lack of training and education (e.g., Sabi et al., 2018) that affect perceptions towards technology and creates resistance to change (Limani et al., 2018).

Outputs: the terms of flexibility, adaptability, resilience and reconfigurability, appear as output variables as they were included in the search equation. It is also clear that "flexibility" is understood differently from

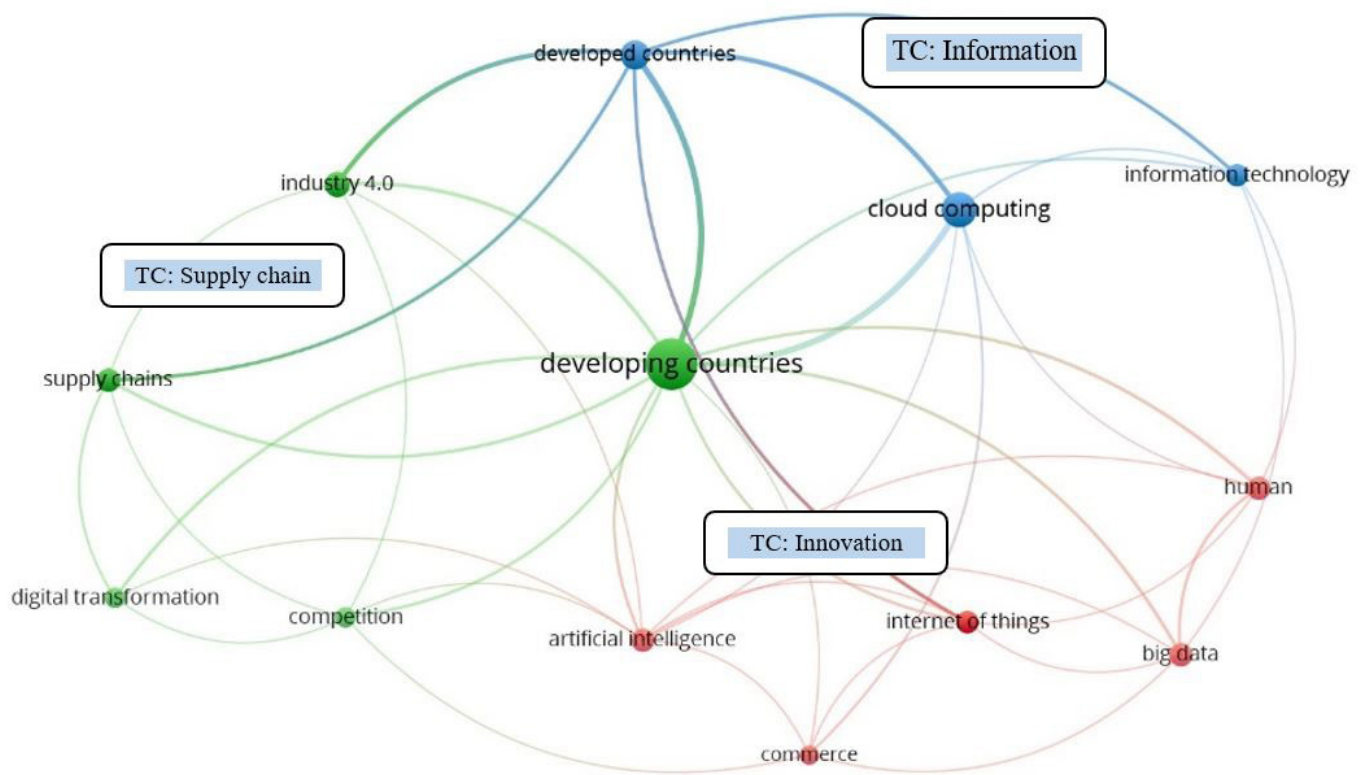

Figure 3. Co-occurrence map and TCs.

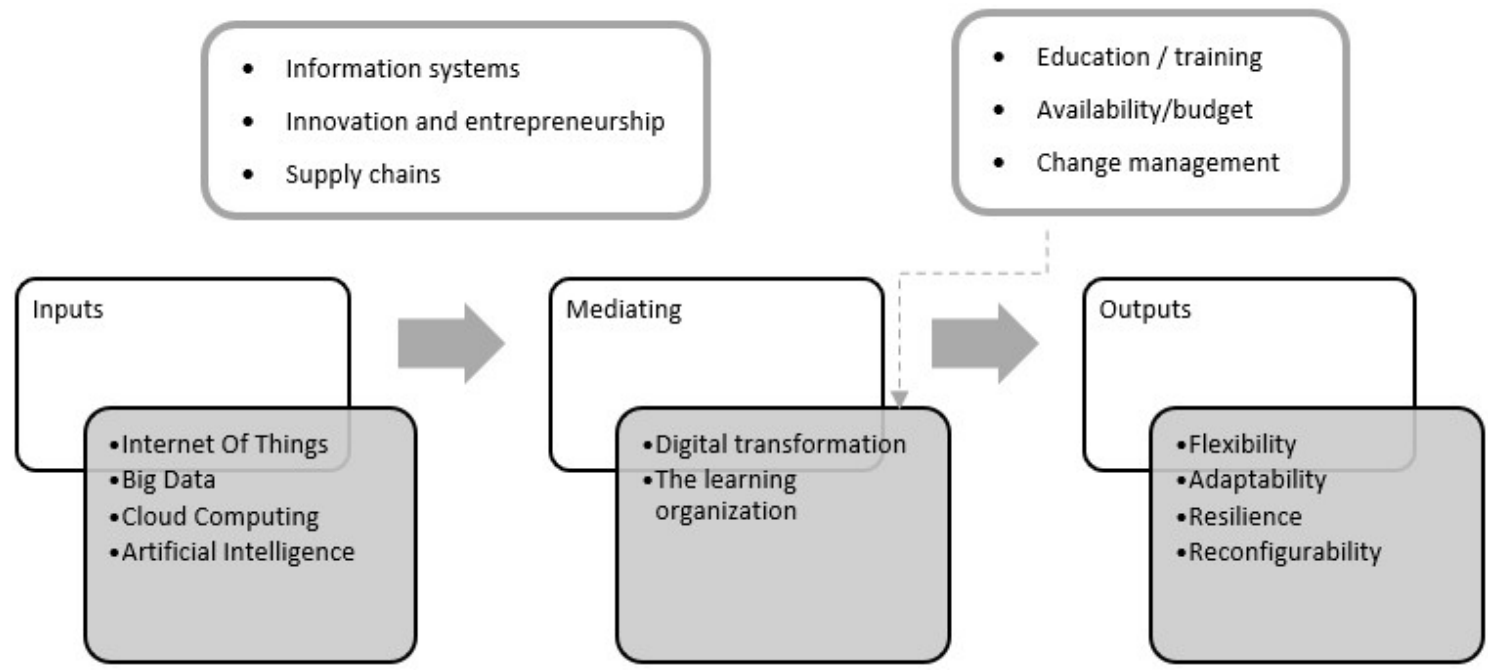

Figure 4. Conceptual framework of the flexibility strategies in Industry 4.0. 
adopters of Cloud Computing in different sectors: in the banking and education organizations, flexibility can be understood as the possibility to quickly update and upgrade their software without the need to purchase or upgrade expensive hardware; in supply chains, flexibility can be understood as the capability of adapting to customer requirements or to unforeseen events such as unexpected peaks of demand and disruptions (e.g. a pandemic). Similar conclusions can also be applied to the other output variables.

Mediating terms: include digital transformation (El-Telbany et al., 2020; Quayson et al., 2020; Ylldırım \& Demirbağ, 2020) and the learning organization (Tjakraatmadja \& Handayani, 2019) that influence the successful implementation of Industry 4.0 technologies whose goals is to improve the performance of organizations in terms of the output variables of the study.

\section{Discussion}

From the above analysis, we can point out that the traditional enablers of flexibility in the framework of Industry 4.0 are mainly technological: in emerging countries, these include mainly cloud computing, and in lesser extent loT, big data and artificial intelligence. Few applications involved digital twins and other cyberphysical systems. These technologies are the basis for more strategic projects such as digital transformation and the "learning organization". It comes as no surprise that the public and the education sectors have been the early adopters of these technologies. The bibliometric review and the cluster analysis suggest that there is a relationship between flexibility and the related terms to the digital transformation. However, more research is needed to truly evaluate its impact not only in terms included in this study but also in financial terms.

This study also suggests that the gap between developing and emerging countries is still large as the adoption rates are still low in the latter countries. Most applications found in the review were mainly related to software aspects and were restricted to individual organizations including universities and schools. No large government-led projects of infrastructure such as intelligent ports, smart cities, or roads with massive use of 14.0 technologies were documented in the reviewed papers.

\section{Conclusions}

By performing a systemic literature review, we identified some common aspects in the context of implementation of Industry 4.0 technologies. In general, there is a consensus that 14.0 is and will be a pillar for improving the flexibility, productivity, an in general the performance of industries in developing countries.

The results also evidence a general concern about the drivers for adoption of Industry 4.0 technologies and the barriers in their implementation in emerging countries or regions, which still has a long way for full adoption due to infrastructure, culture, digital literacy, and security concerns. The framework also illustrates these factors that affect (negatively) its adoption.

Among the technological opportunities offered by Industry 4.0, there was a marked interest for Cloud Computing as opposed to other technologies. This is presumably because it is considered one of the most accessible technologies for the region.

There is also a notable interest in taking advantage of elements of Industry 4.0 in achieving better supply chain integrations, also considering sustainability as an objective to be achieved with the integration of supply chains.

The possibilities of Industry 4.0 (especially cloud computing) have been studied to reduce disparities in education and fill other physical recourses gaps, as the case of deficiencies on university campuses.

\section{References}

Alanezi, M. A. (2018). Factors influencing cloud computing adoption in Saudi Arabia's private and public organizations: a qualitative evaluation. International Journal of Advanced Computer Science and Applications, 9(4), 121-129. http://dx.doi.org/10.14569/ IJACSA.2018.090421.

AlBar, A. M., \& Hoque, M. R. (2019). Factors affecting cloud ERP adoption in Saudi Arabia: an empirical study. Information Development, 35(1), 150-164. http://dx.doi.org/10.1177/0266666917735677.

Alghushami, A. H., Zakaria, N. H., \& Aji, Z. M. (2020). Factors influencing cloud computing adoption in higher education institutions of least developed countries: evidence from Republic of Yemen. Applied Sciences, 10(22), 1-27. http://dx.doi.org/10.3390/app 10228098.

Al-Maatouk, Q., Othman, M. S. Bin., Rana, M. E., \& Al-Rahmi, W. M. (2018). A cloud based framework for e-government implementation in developing countries. IACSIT International Journal of Engineering and Technology, 74), 3018-3021.

Al-Roubaie, A., \& Sarea, A. M. (2020). Rethinking economic development in muslim societies in the context of the Fourth Industria Revolution. Advances in Intelligent Systems and Computing, 1153, 683-695. http://dx.doi.org/10.1007/978-3-030-44289-7_64. 
Araújo, A. F., Varela, M. L. R., Gomes, M. S., Barreto, R. C. C., \& Trojanowska, J. (2018). Development of an intelligent and automated system for lean industrial production, adding, maximum productivity and efficiency in, the, production process. In A. Hamrol, 0. Ciszak, S. Legutko \& M. Jurczyk (Eds.), Advances in manufacturing (Lecture Notes in Mechanical Engineering, pp. 131-140). Cham: Springer. http://dx.doi.org/10.1007/978-3-319-68619-6_13.

Arias-Pérez, J., Velez-Ocampo, J., \& Cepeda-Cardona, J. (2021). Strategic orientation toward digitalization to improve innovation capability: why knowledge acquisition and exploitation through external embeddedness matter. Journal of Knowledge Management, 25(5), 1319-1335. http://dx.doi.org/10.1108/JKM-03-2020-0231.

Bag, S., Telukdarie, A., Pretorius, J. H. C., \& Gupta, S. (2018). Industry 4.0 and supply chain sustainability: framework and future research directions. Benchmarking, BlJ-03-2018-0056. http://dx.doi.org/10.1108/BlJ-03-2018-0056.

Bag, S., Yadav, G., Dhamija, P., \& Kataria, K. K. (2021). Key resources for industry 4.0 adoption and its effect on sustainable production and circular economy: an empirical study. Journal of Cleaner Production, 281, 125233. http://dx.doi.org/10.1016/j.jclepro.2020.125233.

Bazi, H. R., Hasanzadeh, A. R., \& Moeini, A. (2018). Proposaing a novel cloud computing adoption framework using meta-synthesis approach. Iranian Journal of Information Processing Management, 33(2), 549-588.

Boukhris, Y. (2018). Cloud computing and virtualization in developing countries. In AFRICATEK 2017: Emerging Technologies for Developing Countries (Lecture Notes of the Institute for Computer Sciences, Social Informatics and Telecommunications Engineering, Vol. 206, pp. 205-213). Cham: Springer. http://dx.doi.org/10.1007/978-3-319-67837-5_19.

Charrua-Santos, F., Santos, B. P., Enrique, D. V., Alberto, A., Bibete, H., Osório, G. J., \& Lima, T. M. (2020). An overview of lean production and industry 4.0 in different context. In ICITM 2020 - 2020 9th International Conference on Industrial Technology and Management (pp. 69-72). New York: IEEE. https://doi.org/10.1109/ICITM48982.2020.9080386.

Chien, C. F., Hong, T., \& Guo, H.-Z. (2017). A conceptual framework for "industry 3.5" to empower intelligent manufacturing and case studies. Procedia Manufacturing, 11, 2009-2017. http://dx.doi.org/10.1016/j.promfg.2017.07.352.

Dalenogare, L. S., Benitez, G. B., Ayala, N. F., \& Frank, A. G. (2018). The expected contribution of Industry 4.0 technologies for industrial performance. International Journal of Production Economics, 204, 383-394. http://dx.doi.org/10.1016/j.jpe.2018.08.019.

Dolgui, A., lvanov, D., Sethi, S. P., \& Sokolov, B. (2019). Scheduling in production, supply chain and lndustry 4.0 systems by optimal control: fundamentals, state-of-the-art and applications. International Journal of Production Research, 57(2), 411-432. http:// dx.doi.org/10.1080/00207543.2018.1442948.

Elsevier Solutions. (2021). Topic Prominence in Science - Scival. Retrieved in 26 May 2021, from https://www.elsevier.com/solutions/ scival/features/topic-prominence-in-science

Fergencs, T., Pilawka, 0., Broholm, R., \& Magnussen, R. (2020). Barriers to implementing technology-enhanced learning in south african primary schools. In Proceedings of the European Conference on e-Learning (pp. 182-189). ProQuest. https://doi.org/10.34190/ EEL.20.135.

Harlie, M., Hairul, Rajiani, l., \& Abbas, E. W. (2019). Managing information systems by integrating information systems success model and the unified theory of acceptance and usage of technology. Polish Journal of Management Studies, 20(1), 192-201. http:// dx.doi.org/10.17512/pjms.2019.20.1.17.

Irfan, M., \& Wang, M. (2019). Data-driven capabilities, supply chain integration and competitive performance: Evidence from the food and beverages industry in Pakistan. British Food Journal, 121(11), 2708-2729. http://dx.doi.org/10.1108/BFJ-02-2019-0131.

Kacani, J. (2017). Towards knowledge-based flexibility for manufacturing enterprises: with a case study. International Journal of Intelligent Enterprise, 4(3), 204-226. http://dx.doi.org/10.1504/IJIE.2017.087626.

Khayer, A., Jahan, N., Hossain, M. N., \& Hossain, M. Y. (2020). The adoption of cloud computing in small and medium enterprises: a developing country perspective. VINE Journal of Information and Knowledge Management Systems, 51(1), 64-91. http://dx.doi. org/10.1108/VJIKMS-05-2019-0064.

Kumar, D., Samalia, H. V., \& Verma, P. (2017). Exploring suitability of cloud computing for small and medium-sized enterprises in India. Journal of Small Business and Enterprise Development, 24(4), 814-832. http://dx.doi.org/10.1108/JSBED-01-2017-0002.

Lal, P., \& Bharadwaj, S. S. (2016). Understanding the impact of cloud-based services adoption on organizational flexibility: An exploratory study. Journal of Enterprise Information Management, 29(4), 566-588. http://dx.doi.org/10.1108/JEIM-04-2015-0028.

Limani, Y., Stapleton, L., \& Groumpos, P. P. (2018). The challenges of digital transformation in post-conflict transition regions: digital technology adoption in Kosovo. IFAC-PapersOnLine, 51(30), 186-191. http://dx.doi.org/10.1016/j.ifacol.2018.11.284.

Lin, L.-C., \& Hsu, K.-S. (2017). Research on Taiwan's traditional industry strategy planning platform. In 2017 International Conference on Information, Communication and Engineering (ICICE) (pp. 177-180). New York: IEEE. http://dx.doi.org/10.1109/ICICE.2017.8479050.

El-Telbany, O., Abdelghaffar, H., \& Amin, H. (2020, Junio 22). Exploring the digital transformation gap: Evidence from organizations in emerging economies. In Proceedings of the 24th Pacific Asia Conference on Information Systems: Information Systems (IS) for the Future (PACIS 2020). Association for Information Systems. Retrieved in 26 May 2021, from https://aisel.aisnet.org/pacis2020/79

Mallmann, G. L., \& Maçada, A. C. G. (2018). Adoption of cloud computing: a study with public and private hospitals in a developing country. International Journal of Innovation and Technology Management, 15(5), 1-20. http://dx.doi.org/10.1142/S021987701850044X.

Milian, E. Z., Spinola, M. M., \& Carvalho, M. M. (2017). Risks and uncertainties in cloud computing: literature review, trends and gaps. IEEE Latin America Transactions, 15(2), 349-357. http://dx.doi.org/10.1109/TLA.2017.7854632.

Mithun Ali, S., Kumar Paul, S., Chowdhury, P., Agarwal, R., Fathollahi-Fard, A. M., Jose Chiappetta Jabbour, C., Luthra, S., Mohammad Fathollahi-Fard, A., Jose Chiappetta Jabbour, C., \& Luthra, S. (2021). Modelling of supply chain disruption analytics using an integrated approach: an emerging economy example. Expert Systems with Applications, 173, 114690. http://dx.doi.org/10.1016/j. eswa.2021.114690.

Quayson, M., Bai, C., \& Osei, V. (2020). Digital inclusion for resilient post-cOVID-19 supply chains: smallholder farmer perspectives. IEEE Engineering Management Review, 48(3), 104-110. http://dx.doi.org/10.1109/EMR.2020.3006259.

Qvist-Sørensen, P. (2020). Applying lloT and Al: opportunities, requirements and challenges for industrial machine and equipment manufacturers to expand their services. Central European Business Review, 9(2), 46-77. http://dx.doi.org/10.18267/j.cebr.234. 
Raut, R., Priyadarshinee, P., Gardas, B. B., Narkhede, B. E., \& Nehete, R. (2018). The incident effects of supply chain and cloud computing integration on the business performance: an integrated SEM-ANN approach. Benchmarking, 25(8), 2688-2722. http://dx.doi. org/10.1108/BIJ-07-2017-0170.

Sabi, H. M., Uzoka, F. M. E., \& Mlay, S. V. (2018). Staff perception towards cloud computing adoption at universities in a developing country. Education and Information Technologies, 23(5), 1825-1848. http://dx.doi.org/10.1007/s10639-018-9692-8.

Saide, S., \& Sheng, M. L. (2020). Toward business process innovation in the big data era: a mediating roles of big data knowledge management. Big Data, 8(6), 464-477. http://dx.doi.org/10.1089/big.2020.0140. PMid:33216653.

Surajbali, B., Juan-Verdejo, A., Alexakis, S., Bar, H., \& Bauer, M. (2015). A cloud-based collaborative platform supporting servicedenhanced products for emerging markets. In 2014 IEEE International Conference on Cloud Computing in Emerging Markets, CCEM 2014. New York: IEEE. https://doi.org/10.1109/CCEM.2014.7015475.

Tascón, D. C., \& Mejía, G. (2021a). Strategies for flexibility in production systems in industry 4.0: a framework for characterization. In D. Rossit, F. Tohmé \& G. Mejía (Eds.), ICPR-Americas 2020: Production Research (Communications in Computer and Information Science, pp. 330-341). Cham: Springer. http://dx.doi.org/10.1007/978-3-030-76307-7_25.

Tascón, D. C., \& Mejía, G. (2021b). Estrategias de flexibilización de los sistemas de producción en la industria 4.0: un marco para su caracterización. In D. Rossit, F. Tohmé \& G. Mejía (Eds.), Proceedings of the 10th International Conference of Production ResearchAmericas (pp. 1341-1355). Bahía Blanca: Editorial de la Universidad Nacional del Sur. Retrieved in 26 May 2021, from https://www. matematica.uns.edu.ar/ipcra/pdf/icpr_americas_2020_proceedings.pdf

Tjakraatmadja, J. H., \& Handayani, D. W. (2019). Mapping six characteristics of new learning organization in Indonesian education technology startups. In Proceedings of the International Conference on Intellectual Capital, Knowledge Management and Organisational Learning (pp. 340-347). England: Academic Conferences International. https://doi.org/10.34190/lKM.19.033.

Turkyilmaz, A., Dikhanbayeva, D., Suleiman, Z., Shaikholla, S., \& Shehab, E. (2021). Industry 4.0: challenges and opportunities for Kazakhstan SMEs. Procedia CIRP, 96, 213-218. http://dx.doi.org/10.1016/j.procir.2021.01.077.

Varela, L., Araújo, A., Ávila, P., Castro, H., \& Putnik, G. (2019). Evaluation of the relation between lean manufacturing, industry 4.0, and sustainability. Sustainability, 11(5), 1439. http://dx.doi.org/10.3390/su11051439.

Wilson, B. M. R., Khazaei, B., \& Hirsch, L. (2016). Enablers and Barriers of Cloud Adoption among Small and Medium Enterprises in Tamil Nadu. In Proceedings - 2015 IEEE International Conference on Cloud Computing in Emerging Markets, CCEM 2015 (pp. 140-145). New York: IEEE. https://doi.org/10.1109/CCEM.2015.21.

Yıldırım, N., \& Demirbağ, K. Ș. (2020). From chaos to calm: industry 4.0 practices of turkish white goods companies. In ISPR 2019: Proceedings of the International Symposium for Production Research 2019 (pp. 278-287). Cham: Springer. https://doi.org/10.1007/9783-030-31343-2 24 . 